\title{
Initiation of Dynamic Recrystallization of As-Cast N08028 Alloy
}

Elena Mora, Aitor Navarro, Elena Silveira, Cecilia Poletti, Joseba Mendiguren and Iñaki Hurtado

Elena Mora. Department of Mechanical and Industrial Production, Mondragon Unibertsitatea, Loramendi 4, Mondragon 20500,

Gipuzkoa, Spain

Corresponding author: emora@mondragon.edu

Aitor Navarro. Tubacex Innovación AIE, Parque Científico y Tecnológico de Bizkaia, Astondo Bidea, Edificio 702, Derio, Bizkaia, Spain

Elena Silveira. Tecnalia, Parque Tecnológico de San Sebastian, Mikeletegi Pasealekua, 2, 20009 Donostia-San Sebastián, Gipuzkoa, Spain

Cecilia Poletti. Institute of Materials Science, Joining and Forming at Graz University of Technology, Kopernikusgasse 24/I, 8010 Graz, Austria

Joseba Mendiguren. Department of Mechanical and Industrial Production, Mondragon Unibertsitatea, Loramendi 4, Mondragon 20500, Gipuzkoa, Spain

Iñaki Hurtado. Department of Mechanical and Industrial Production, Mondragon Unibertsitatea, Loramendi 4, Mondragon 20500, Gipuzkoa, Spain

Abstract. The use of high nickel content austenitic stainless steels (SASS) has significantly increased in the last decade. The corrosion and high fatigue resistance of these materials make them suitable for manufacturing oil country tubular goods (OCTG). SASS are processing by forging from casting conditions. Dynamic recovery (DRV) and recrystallization (DRX) of as-cast super austenitic stainless steel, N08028 Alloy, is investigated to study the refining effect from the as-cast grain structure to fully recrystallized austenite due to hot deformation. Both the critical stress and strain for the initiation of DRX are determined using the flow curves. To perform this analysis, hot compression tests are performed at temperatures between $900^{\circ} \mathrm{C}$ and $1250{ }^{\circ} \mathrm{C}$, and strain rates between $0.1 \mathrm{~s}^{-1}$ and $10 \mathrm{~s}^{-1}$, up to 0,8 final strain using a Gleeble®3800 thermomechanical simulator. Subsequently, the Johnson-Avrami-Mehl-Kolmogorow (JMAK) model is used to numerically fit the flow curves and consequently determine the critical strain. No critical points are seen for temperatures under $1100^{\circ} \mathrm{C}$. Above this temperature, the JMAK model proves to be valid in all studied strain rates.

Keywords. Critical Strain, Dynamic, Recrystallization, Austenitic Stainless Steel, Hot Compression Test

\section{Introduction}

N08028 Alloy is widely used in chemical and petrochemical industry due to its excellent corrosion resistance and its large yield strength [1]. Its workability is poor and the hot working range is narrow. During thermos-mechanical treatments dynamic recovery (DRV) and dynamic recrystallization (DRX) are the most important restoration mechanisms. They affect the final microstructure and, therefore, the mechanical properties. The hot deformation behavior of the Alloy N08028 during a hot extrusion process was studied by Wang et al. [2], who found that this alloy undergoes DRX due to its low stacking fault energy of N08028 Alloy [3]. However, the stacking fault energy varies depending on the initial state of the material. Huiqin et al. [4] studied for the Mn18Cr18N stainless steel, and compared the activation energy for both as-cast and wrought starting structures, concluding that the as-cast samples presents a higher energy than the wrought samples.

Significant differences exist between as-cast ingots and as-forged billets. These include the grain sizes, morphologies, and solidification textures. These factors, strongly affect the hot-working ability, microstructural evolution, and mechanical properties of the final material [5]. Hence, it is important to investigate the critical conditions of DRX initiation of as-cast SSAS alloys during hot working. 
The onset of DRX can be identified as phenomenological from the inflection point in the strain-hardening rate $(\theta)$ versus flow stress $(\sigma)$ curve. E.I. Poliak and J.J. Jonas [6] have shown that this corresponds to the appearance of an additional thermodynamic degree of freedom in the system. The critical stress identifies the moment when dynamic recrystallization begins to contribute to decreasing the flow stress [7] due to strong reduction of the dislocations density.

In this study, the critical conditions for initiation of DRX of as-cast Alloy N08028 are investigated by using hot compression test at different strain rate and temperature conditions. The critical strain is calculated using the work hardening rate versus the flow stress curves, and validated using the JMAK model in all studied conditions. Electron backscattered diffraction (EBSD) analysis are used to identify the recrystallization state after hot deformation.

\section{Experimental}

The UNS N05028 alloy with the chemical composition of $0.033 \mathrm{wt} \% \mathrm{C}-25.84 \mathrm{wt} \% \mathrm{Cr}-29.88 \mathrm{wt} \% \mathrm{Ni}-3.06 \mathrm{wt} \% \mathrm{Mo}$ and $0.83 \mathrm{wt} \% \mathrm{Mn}$ is used in this work. Cylindrical specimens with height of $15 \mathrm{~mm}$ and diameter of $10 \mathrm{~mm}$ were obtained from a $5 \mathrm{t}$ as-cast billet and homogenized at a temperature of $1250^{\circ} \mathrm{C}$ for $4 \mathrm{~h}$ before the hot compression test.

The compression tests are carried out using a Gleeble $₫ 3800$ - thermomechanical simulator in a temperature range of $1100^{\circ} \mathrm{C}-1250^{\circ} \mathrm{C}$ and a strain rate range of $0.01-10 \mathrm{~s}^{-1}$. Tantalum and graphite foils, are used for lubrication. A thermocouple was spot-welded to the longitudinal center of the specimen. All specimens were compressed to a strain 0.8 and then, immediately water quenched to room temperature. The compressed samples are sectioned along the axis, and common metallographic preparation is conducted, wich consist of successive wet grinding from 240 grit paper until 1200 grit, followed by a three step polishing, first consecutive $3 \mu \mathrm{m}$ and $1 \mu \mathrm{m}$ diamond paste, and a final step of Alluminum $0.3 \mu \mathrm{m}$ suspension. The transversally sectioned samples microstructures were analyzed then by optical microscopy (OM) and electron backscatter diffraction (EBSD). For the EBSD preparation, after the last preparation step, the samples are polished on a vibration machine using a $0.1 \mu \mathrm{m}$ aluminum suspension for 4 hours.

\section{Results and discussion}

\subsection{Stress-strain curves}

The flow curves obtained at different temperatures and strain rates are shown in Fig. 1, where the flow curves are dependent on the temperature and strain rate. At the same strain rate and strain, the flow stress increases with the decrease of deformation temperature. At the same deformation temperature and strain, the flow stress increases with the increase of strain rate. 

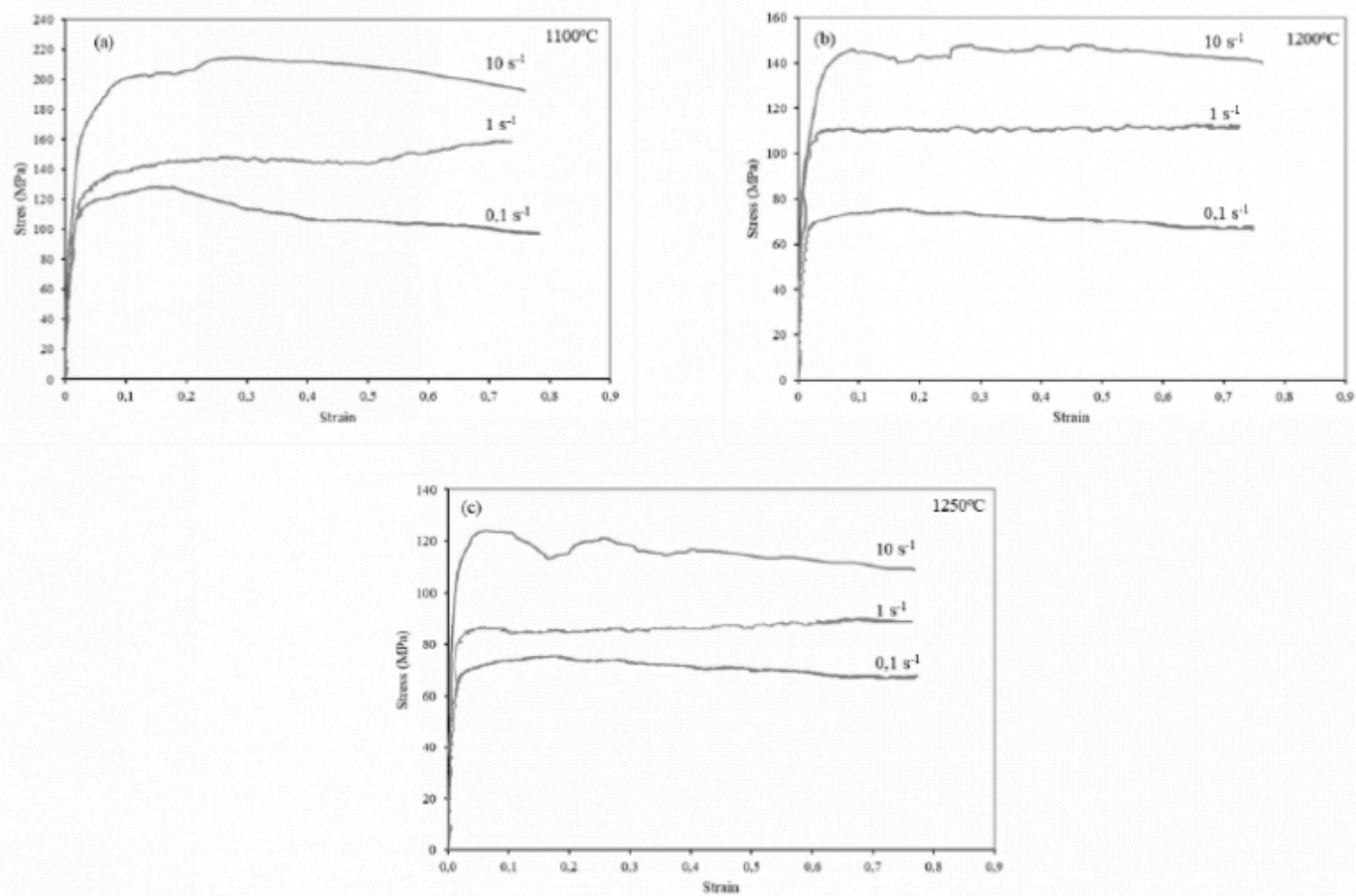

Fig. 1. Stress-strain curves under different deformation conditions: (a) $\mathrm{T}=1100^{\circ} \mathrm{C}$ (b) $\mathrm{T}=1200{ }^{\circ} \mathrm{C}$ (c) $\mathrm{T}=1250{ }^{\circ} \mathrm{C}$ and

$$
0.1 \mathrm{~s}^{-1}, 1 \mathrm{~s}^{-1}, 10 \mathrm{~s}^{-1}
$$

The hot deformation behavior of the N08028 Alloy coming from an initial microstructure of rough equiaxed grains with a large number of twin boundaries, consist of three stages [8]. (I) Work Hardening (WH) and DRV before the critical strain $\left(\varepsilon_{c}\right)$. In this stage, the flow stress rapidly rises at small strain. If DRX does not occur, a balance between the WH and DRV is gradually reached resulting in a saturated stress ( $\left.\sigma_{\text {sat }}\right)$. (II) In this Alloy, WH, DRV and DRX coexist after the critical strain $\left(\varepsilon_{c}\right)$ is reached. In this stage, at the beginning of DRX, the increase of dislocation density induced by WH is dominant and the flow stress still increases with increasing strain. Due to the DRV and DRX competing phenomena, the dislocation density abruptly decreases when the deformation degree is larger than the peak strain $\left(\varepsilon_{p}\right)$. (III) The rate of nucleation and the rate of grain boundary migration will balance each other and the flow stress, as well as the microstructural features (grain sizes, dislocation densities), remain constant with further strain reaching steady state.

The flow stress of the as-cast samples (Fig. 1) exhibit peaks at very large strains. This may be due to the preferred crystallographic texture, due to the late initiation of DRX, that will have an influence on the reproducibility of the test. Along with this, it can be seen that the curves don't reach the steady-state. Since the DRX occurs at grain boundaries and the initial grains are quite large, the nucleation rate can be rather small, due to the low amount of nucleation sites. Furthermore, large grains could produce many chains of DRX grains. This behavior can be related with the multiple peaks flow curves.

\subsection{Predicting the critical strain and peak strain}

To determine the critical strain $\varepsilon_{\mathrm{c}}$ for the on set of DRX, the double-differentiation method proposed by Poliak and Jonas [9] and simplified by Najafizadeh and Jonas [10], is employed in the present investigation. Firstly, the flow curves 
are smoothed and fitted with a seventh-order polynomial using the Origin Software. (In some problematic cases, a higher order polynomial is employed.) Then, the work-hardening rate $\theta=d \sigma / d \varepsilon$ is calculated an plotted against the true stress. This method defines $\varepsilon c$ as the point at which the second derivative of the work-hardening rate with respect to stress is zero, i.e, the inflection point of $\theta-\sigma$ curve, as is shown in Fig. 2.

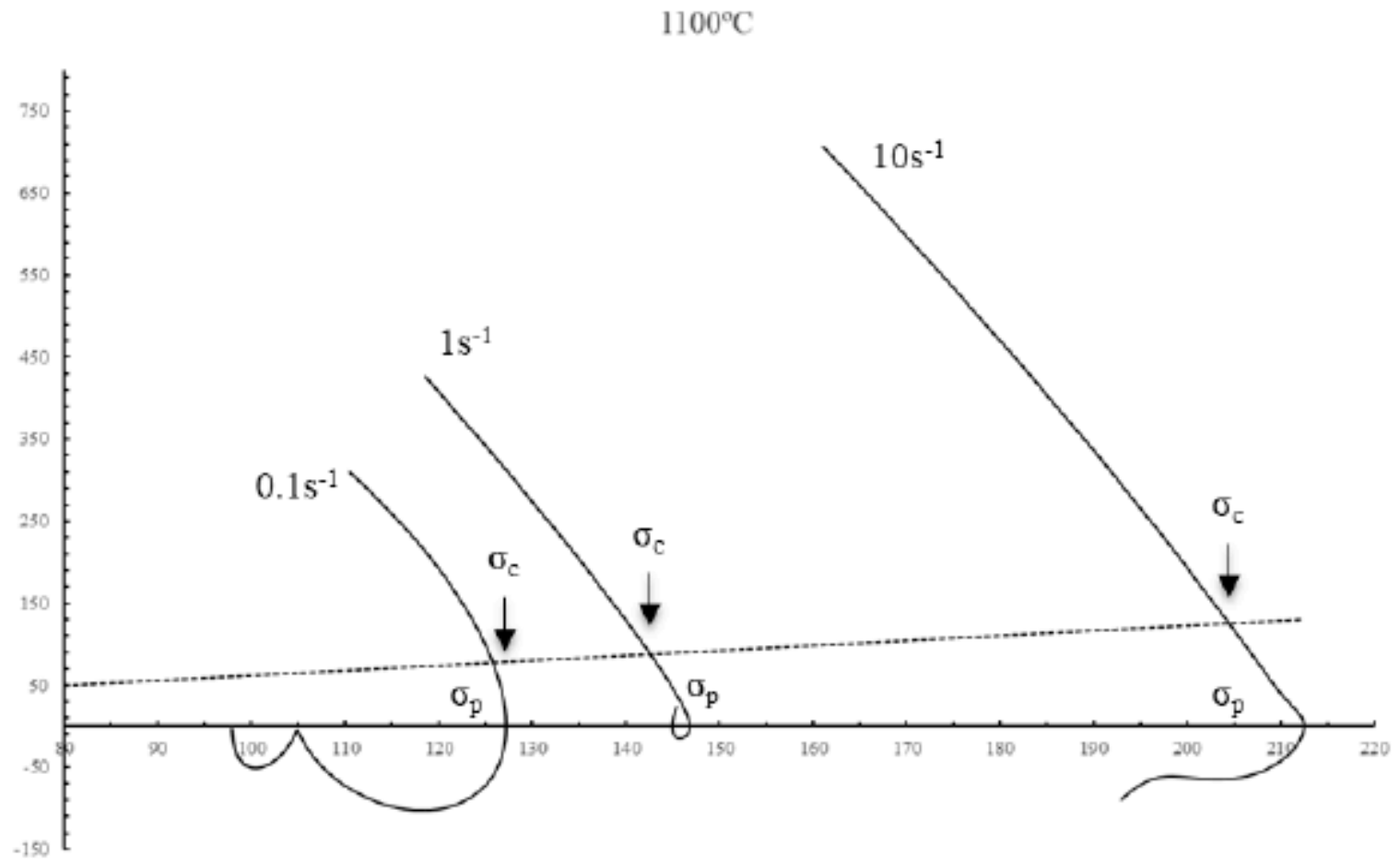

Fig. 2. Experimental stress-strain curve determined at $1100^{\circ} \mathrm{C}$ for the Alloy N08028

Based on the $\theta-\sigma$ curves, the values of $\sigma_{\mathrm{c}}$ and $\sigma_{\mathrm{p}}$ of the As-cast Alloy N08028 under different deformation conditions were easily computed, then, the values of $\varepsilon_{\mathrm{c}}$ and $\varepsilon_{\mathrm{p}}$ were obtained based on the values of $\sigma_{\mathrm{c}}, \sigma_{\mathrm{p}}$ and true strain-stress curves.

Based on literature [11], the peak strain is often represented as a function of the thermomechanical and can be described as follows:

$$
\begin{gathered}
\varepsilon_{p}=k d_{0}^{n} Z^{m_{1}} \\
\varepsilon_{\mathrm{p}}=K Z^{m_{1}}
\end{gathered}
$$

where $K, k, n$ and $m_{1}$ are material dependent constant; $d_{0}$, is the initial grain size; and $\mathrm{Z}$ is the Zener-Hollomon parameter $\left(\mathrm{s}^{-1}\right)$, defined as follows: 


$$
Z=\dot{\varepsilon} \exp \left(\frac{Q_{h w}}{R T}\right)
$$

where $\dot{\varepsilon}$ is the strain rate $\left(\mathrm{s}^{-1}\right), Q_{\mathrm{hw}}$ is the activation energy for hot deformation $\left(\mathrm{J} \mathrm{mol}^{-1}\right), R$ is the universal gas constant $\left(\mathrm{J} \mathrm{mol}^{-1} \mathrm{~K}^{-1}\right)$, and $T$ is the absolute temperature $(\mathrm{K})$. These expressions have been developed empirically and take into account the influence of the initial microstructure, through the grain size prior to deformation $d_{0}$, and the deformation conditions through the Zener-Hollomon parameter $Z$ [11].

The overall kinetics of recrystallization are typically described by the JMAK relation relationship. In this empirical model, the fraction of recrystallized material, denoted $\chi$, evolves through:

$$
\chi(t)=1-e^{-b t^{n}}
$$

where $b$ and $n$ are the Avrami coefficients, whose values depend on the growth and nucleation rates. This model is able to globally describe nucleation growth and impingement of the growing grains [12].

For this work, an approach of the JMAK model is used. This model allows predicting recrystallized fractions and grain sizes evolution during a thermomechanical treatment. Accordingly, the following equation can be used to obtain the critical strain [13]:

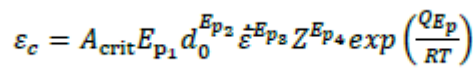

where $A_{\mathrm{crit}}, E_{\mathrm{p} 1}, E_{\mathrm{p} 2}, E_{\mathrm{p} 3}$ and $E_{\mathrm{p} 4}$ are the materials parameters to be determined experimentally, $d_{0}$ is the initial average grain diameter. $Q_{\text {ep }}$ is the apparent activation energy calculated as $501.21 \mathrm{KJ} / \mathrm{mol}$. According to bibliography, for the wrought alloy $\mathrm{N} 08028$ is around $400 \mathrm{KJ} / \mathrm{mol}$ [8], so as it was expected according to Chen et al. [4], the activation energy of as-cast samples is higher than the wrought samples.

Comparison between the experimental and predicted results is shown in Fig. 3. It can be found that the predicted results well agree with the experimental ones, which indicates that the proposed models can fit an accurate estimate of peak strain for the studied Alloy. 


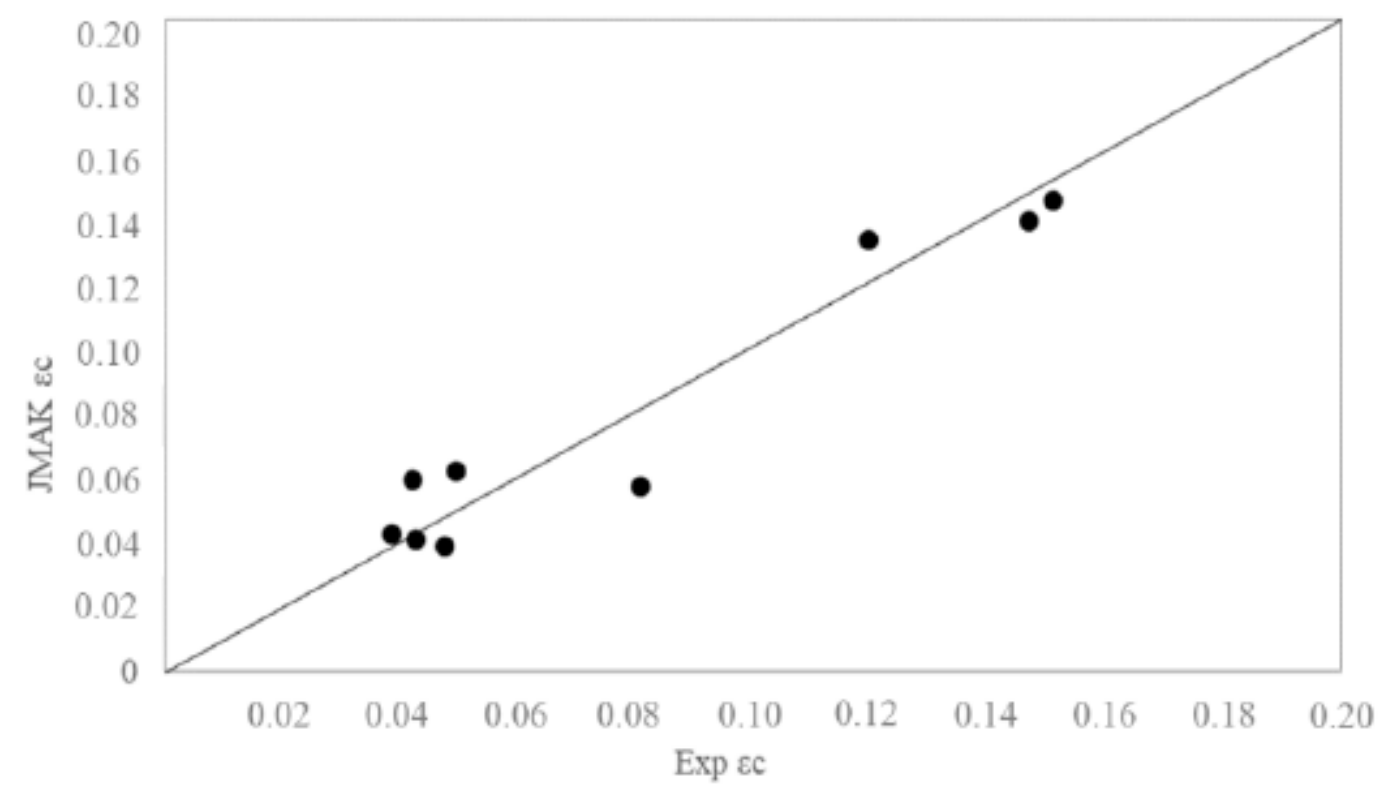

Fig. 3. Comparison between the experimental and predicted critical strain

\subsection{Microstructural examination}

The as-cast microstructure of the thermally processed ingot, shown in Fig. 4, is composed of large grains with an average size of $4.55 \mathrm{~mm}$ determined according to ASTM E1181-02.

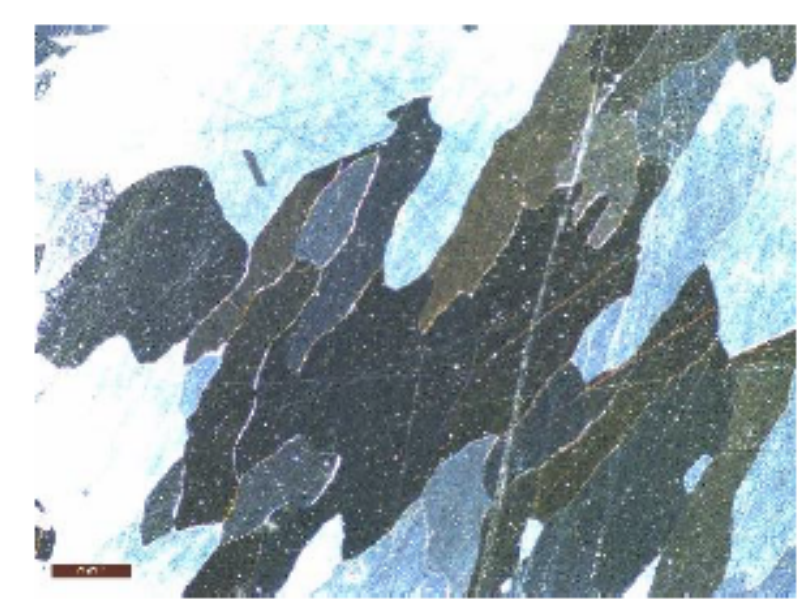

Fig. 4. Initial Microstructure

The EBSD grain boundaries map for the lowest strain rate at each temperature tested is shown in Fig 3. It should be expected that the mayor recrystallization take place at lower strain rates. Due to the high activation energy and the initial large grains present in the initial microstructure, a higher or total recrystallization is not expected for studied material, and mayor strain will be necessary to reach the total recrystallized state. 


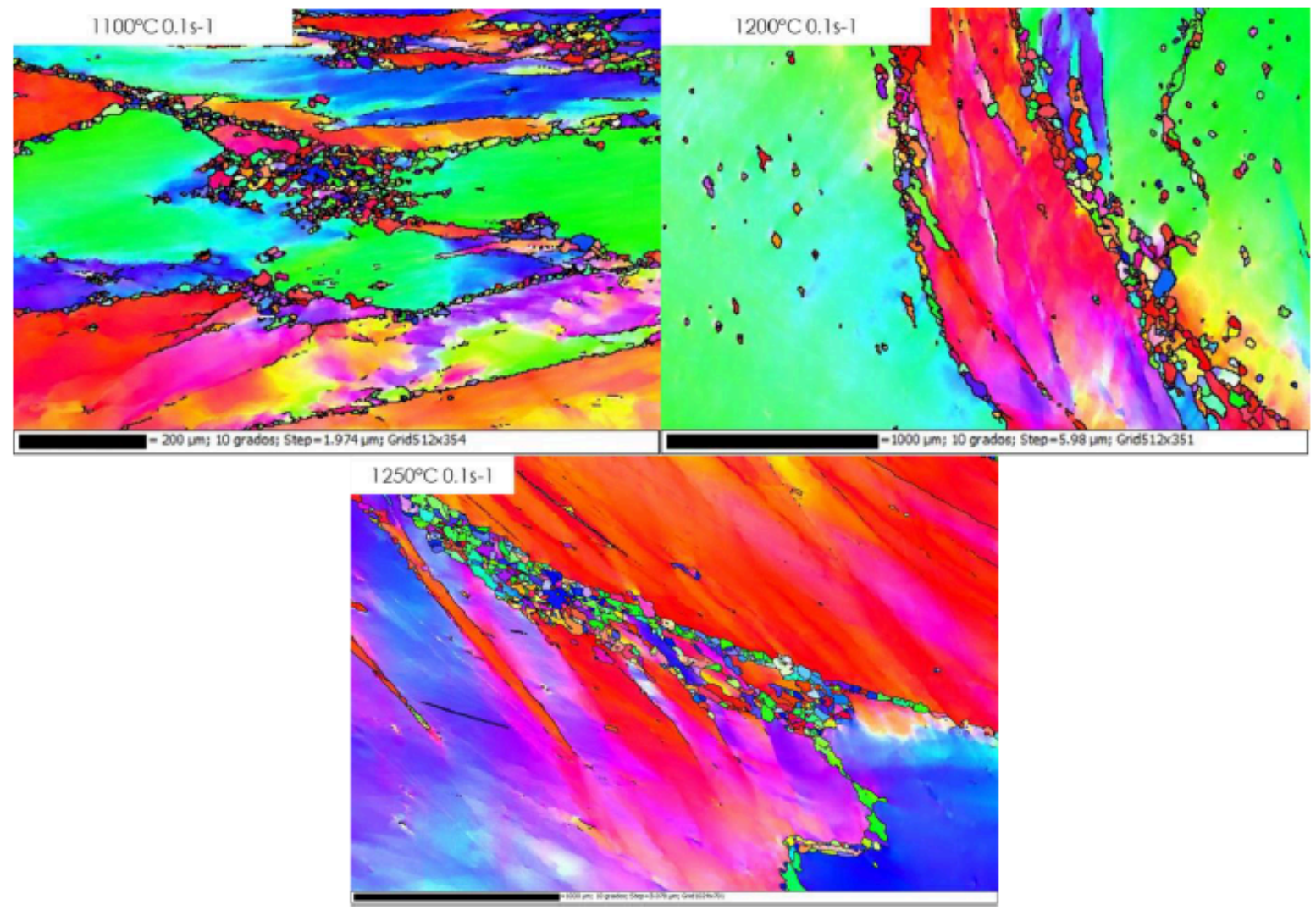

Fig. 5. EBSD maps under $1100^{\circ} \mathrm{C}, 1200^{\circ} \mathrm{C}, 1250^{\circ} \mathrm{C}$ at $0.1 \mathrm{~s}^{-1}$

As it can be observed, the recrystallized structure, presented the large initial grains, and the recrystallized nucleated grains have developed in the grain boundaries. Due to this heterogeneous microstructure, microstructural observations (MO) are used to complement the EBSD measurements at lower magnifications. In Fig. 6 the recrystallized grains (red arrows) for the $1100^{\circ} \mathrm{C}$ and $0.1 \mathrm{~s}^{-1}$ specimens are observed along the grain boundaries of the large deformed grains. The microstructure shows the low amount of new recrystallized grains along with the high-deformed grains. The microstructures confirm the initial observations for the EBSD analysis, that, total recrystallization will not be possible for the tested strain. 

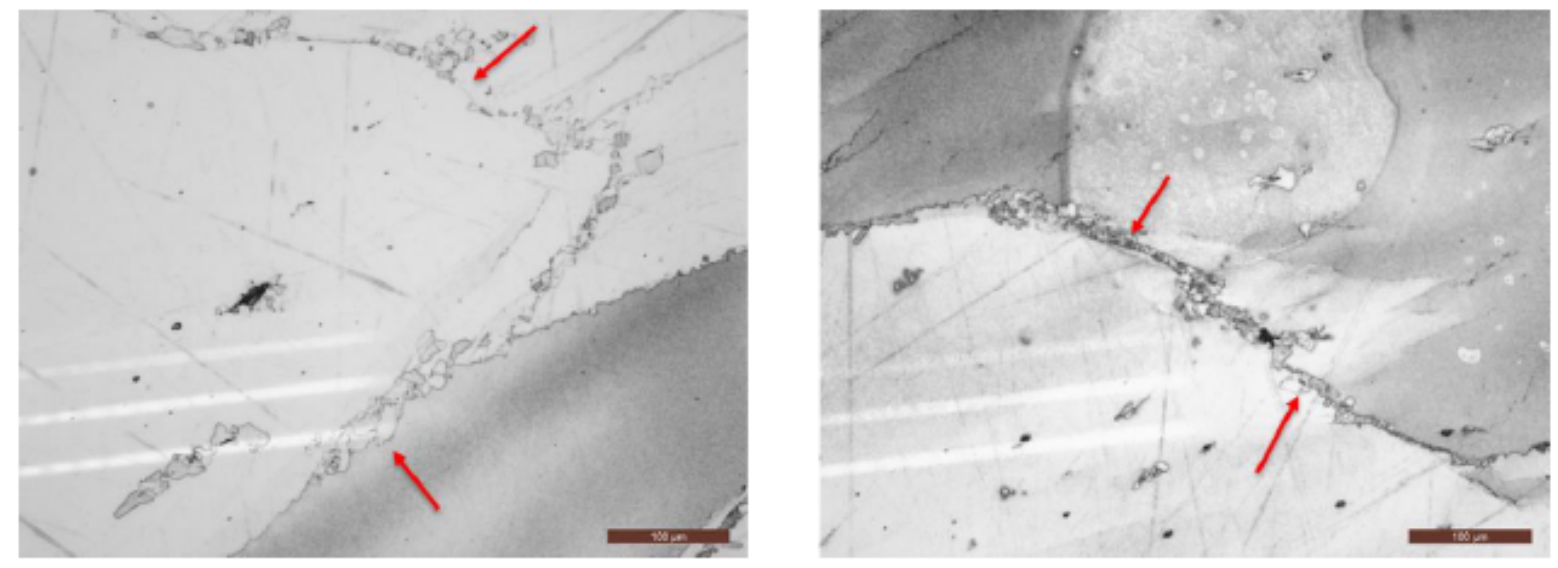

Fig. 6. $\mathrm{OM}$ for the $1100^{\circ} \mathrm{C}$ and $0.1 \mathrm{~s}^{-1}$ specimen

\section{Summary and Conclusions}

In this study, the effects of deformation parameters on the DRX behavior in As-cast alloy were discussed. The kinetic equations were developed to predict the DRX behavior in as-cast N08028 Alloy, which is sensitive to the deformation temperature and strain rate.

From the Stress-Strain curves, it was found that the DRX in as-cast N08028 Alloy occurs at higher deformation than wrought material, according with previous studies by Wang et al. [2]. From the obtained critical strains, the initiation of DRX was predicted and according with the EBSD images, the recrystallization was initiated. Nerveless, according with the higher initiation energy, larger strains are need for a fully recrystallized structure.

A good agreement between the experimental and predicted results indicates that the proposed kinetic equations can give an average prediction, and can be used as a first approach to analyze the microstructural evolution during the forming process.

\section{Acknowledgements}

The Authors would like to acknowledge the partial support from the Research Project "ALYMICRO microstructural and corrosion phenomena modeling analysis for casting and forging for the Alloy 28" in partnership with TECNALIA and TUBACEX.

\section{Bibliography}

[1] N. Eftekhari, W. Muhammad, F. Haftlang, A. Zarei-Hanzaki, and É. Martin, "Microstructural evolution and corrosion behavior of Sanicro 28 during thermomechanical processing," Mater. Today Commun., vol. 24, no. March, p. 101228, 2020.

[2] L. Wang, F. Liu, Q. Zuo, and C. F. Chen, "Prediction of flow stress for N08028 alloy under hot working conditions," Mater. Des., vol. 47, pp. 737-745, 2013.

[3] M. Moallemi, A. Zarei-hanzaki, and A. Mirzaei, "On the Stacking Fault Energy Evaluation and Deformation Mechanism of Sanicro-28 Super-Austenitic Stainless," J. Mater. Eng. Perform., vol. 24, no. June, pp. 2335-2340, 2015. 
[4] C. Huiqin, H. Wenwu, Z. Xiaodong, Q. Fengming, and W. Zhenxing, "ScienceDirect Hot deformation behavior and dynamic recrystallization of Mn18Cr18N steel with as-cast versus wrought starting structures," Procedia Eng., vol. 207, pp. 1779-1784, 2017.

[5] B. Xie, B. Zhang, Y. Ning, and M. W. Fu, "Mechanisms of DRX nucleation with grain boundary bulging and subgrain rotation during the hot working of nickel-based superalloys with columnar grains," J. Alloys Compd., 2019.

[6] E. I. Poliak and J. J. Jonas, “Critical Strain for Dynamic Recrystallization in Variable Strain,” vol. 43, no. 5, pp. 692700, 2003.

[7] M. R. Barnett et al., "Predicting the Critical Stress for Initiation of Dynamic Recrystallization," vol. 46, no. 11, pp. 1679-1684, 2006.

[8] L. Wang and F. Liu, "Dynamic Recrystallization Behavior of N08028 Corrosion Resistant Alloy," Mater. Sci. Forum, vol. 788, pp. 396-405, 2014.

[9] E. I. Poliak and J. J. Jonas, "Initiation of Dynamic Recrystallization in Constant Strain Rate," vol. 43, no. 5, pp. 684691, 2003.

[10] H. Mirzadeh and A. Najafizadeh, "Prediction of the critical conditions for initiation of dynamic recrystallization," Mater. Des., vol. 31, no. 3, pp. 1174-1179, 2010.

[11] G. Varela-castro, “Critical Strain for Dynamic Recrystallisation . The particular case of steels,” 2020.

[12] F. J. Humphreys and M. Hatherly, “Chapter 7 - Recrystallization of Single-Phase Alloys,” Recryst. Relat. Annealing Phenom. (Second Ed., pp. 215-IV, 2004.

[13] Transvalor, "Part 8 : Metallurgy Table of Contents : On the modelling scope for FORGE."

PDF automatically generated on 2021-05-20 08:33:05

Article url: https://popups.uliege.be/esaform21/index.php?id=896 published by ULiège Library in Open Access under the terms and conditions of the CC-BY License (https://creativecommons.org/licenses/by/4.0) 